\title{
Fractal structures and fractal functions as disease indicators
}

\author{
J. M. Escós, C. L. Alados and J. M. Emlen
}

Escós, J. M., Alados, C. L. and Emlen, J. M. 1995. Fractal structures and fractal functions as disease indicators. - Okkos 74: 310-314.

\begin{abstract}
Developmental instability is an early indicator of stress, and has been used to monitor the impacts of human disturbance on natural ecosystems. Here we investigate the use of different measures of developmental instability on two species, green peppers (Capsicum annum), a plant, and Spanish ibex (Capra pyrenaica), an animal. For green peppers we compared the variance in allometric relationship between control plants, and a treatment group infected with the tomato spotted wilt virus. The results show that infected plants have a greater variance about the allometric regression line than the control plants. We also observed a reduction in complexity of branch structure in green pepper with a viral infection. Box-counting fractal dimension of branch architecture declined under stress infection. We also tested the reduction in complexity of behavioral patterns under stress situations in Spanish ibex (Capra pyrenaica). Fractal dimension of head-lift frequency distribution measures predator detection efficiency. This dimension decreased under stressful conditions, such as advanced pregnancy and parasitic infection. Feeding distribution activities reflect food searching efficiency. Power spectral analysis proves to be the most powerful tool for characterizing fractal behavior, revealing a reduction in complexity of time distribution activity under parasitic infection.
\end{abstract}

J. M. Escós and C. L. Alados, Instituto Pirenaico de Ecología (CSIC), Avda. Montañana 177, Aptdo. 202, E-50080 Zaragoza, Spain. - J. M. Emlen, Pacific Northwest Natural Science Center (NBS), Bldg 204, Naval Station, Seattle, WA 98115, USA.

Stress is an energy dissipative process (Parsons 1993) that consumes energy otherwise available for growth and reproduction. Under stress conditions, environmental fluctuations, together with the lack of enough energy available for homeostatic buffering, lead to increased variation in the development of structures under identical genetic and environmental influence (e.g., left and right sides of bilaterally symmetric organisms). This increased variance is known as developmental instability (Waddington 1957). Many empirical studies have demonstrated that stress increases random variation in normally bilaterally symmetric traits i.e. fluctuating asymmetry. (Zakharov 1987, Parsons 1992, Graham et al. 1993, for a review). But bilateral symmetry is only one within-individual developmental invariant. Deviations in radial symmetry or symmetry of scale (Graham et al. 1993, Freeman et al. 1993) are also useful in detecting stress. The ar- rangement of leaves on a stem often follows a consistent Fibonacci sequence, that optimizes the acquisition of light and resource distribution. Internode length often follows a simple self-similar (or self-affine) sequence where internode order (counted from the stem base) is interpreted as a scaling factor. The error of the curve fitting is a good estimator of the scale asymmetry, defined as error in the repetition of an object at different spatial scales, and thus, of developmental instability (Paxman 1956, Freeman et al. 1993, Alados et al. 1994). A decline in accuracy of the curve fit is expected under stress situations.

But increased variability is not the only consequence of stress. In some structures energy flow as well as environment nutrient exchange is enhanced by fine strucutre (e.g. of blood vessels, bronchial tree, neurites) (Frontier 1987, West and Goldberger 1987, Goldberger et

Accepted 20 March 1995

Copyright (C) OKOS 1995

ISSN 0030-1299

Printed in Denmark - all rights reserved 
Table 1. One way analyses of variance, with curve fitting indexes $\left(\mathrm{Sa}, \mathrm{Syx}, \mathrm{R}^{2}\right)$ and regression parameters $(\mathrm{k}$, a and $\mathrm{b}$ ) as dependent variables and treatment as fixed factor, in the leaf arrangement equations of green pepper.

$\mathrm{L}=\mathrm{kN} \mathrm{N}^{\mathrm{a}} \mathrm{e}^{-\mathrm{bN}}$

\begin{tabular}{lrrrc}
\hline $\begin{array}{l}\text { Source of } \\
\text { variation }\end{array}$ & df & SS & $\mathrm{F}$ & $\mathrm{P}$ \\
\hline Sa & 1,37 & 1.54 & 31.48 & 0.000 \\
Syx & 1,36 & 1.20 & 152.20 & 0.000 \\
$\mathrm{R}^{2}$ & 1,37 & 2.92 & 97.43 & 0.000 \\
$\mathrm{k}$ & 1,37 & 20.38 & 19.36 & 0.000 \\
$\mathrm{a}$ & 1,37 & 35.87 & 11.74 & 0.002 \\
$\mathrm{~b}$ & 1,37 & 5.77 & 7.04 & 0.01 \\
\hline Means & \multicolumn{5}{c}{ Control } & \multicolumn{3}{c}{ Infected } \\
\hline & $0.34 \pm 0.05(19)$ & $0.74 \pm 0.05(20)$ \\
Sa & $0.18 \pm 0.02(19)$ & $0.53 \pm 0.02(19)$ \\
Syx & $0.89 \pm 0.04(19)$ & $0.35 \pm 0.04(20)$ \\
$\mathrm{R}^{2}$ & $4.69 \pm 0.23(19)$ & $3.25 \pm 0.23(20)$ \\
$\mathrm{k}$ & $1.71 \pm 040(19)$ & $-0.21 \pm 0.39(20)$ \\
$\mathrm{a}$ & $-0.61 \pm 0.21(19)$ & $0.16 \pm 0.20(20)$ \\
$\mathrm{b}$ & & &
\end{tabular}

al. 1990). In trees, branch structure allows sufficient contact between the atmosphere and chlorophyll to perform photosynthesis efficiently. The self-similar nature of branches provides a useful way to measure complexity by its fractal dimension. In these structures stress can be expected to reduce complexity. Decreased fractal dimension under stress has been found in previous studies (Alados et al. 1994).

Physiological and behavioral responses, as well as morphological irregularities, can be used to detect stress. A number of diseases are characterized by a loss of the variability associated with fractal strucutures (West and Golberger 1987, Weinstein et al. 1992, Cross et al. 1993, Boxt et al. 1994) and functions (Waddington et al. 1979, West and Goldberger 1987, Golberger et al. 1990, Butler et al. 1993). A loss of physiological variability in a variety of systems appears to be characteristic of the aging process (Waddington et al. 1979, West and Goldberger 1987). West (1990) argues that fractal processes are more adaptive to internal and environmental changes than non-fractal ones since they are error tolerant.

\section{Methods}

To analyze the effect of viral infection (tomato spotted wilt virus, TSWV) on the scale invariance of leaf arrangement in green pepper, we collected samples from two different populations under plastic protected facilities, in the Mojonera Experimental Station (INIA), Spain. Twenty plants were infected with TSWV virus and 19 plants served as controls. Internode length was measured from botton to top. Curve fitting accuracy was calculated for each inividual plant. The plants fit the equation $\mathrm{L}=\mathrm{k} \cdot \mathrm{N}^{\mathrm{i}} \cdot \mathrm{e}^{-\mathrm{b} \mathrm{N}}$, where $\mathrm{L}$ is intemode length, $\mathrm{N}$ is node order, and $\mathrm{k}$, $\mathrm{a}$ and $\mathrm{b}$ are fitted parameters. After linearizing the equation by $\log$-log regression analyses, the uncertainty of the curve fitting, measured as the standard error of the regression $S_{y x}$, standard error of the slope $S_{a}$, and the coefficient of determination $R^{2}$ are good estimators of the scale asymmetry. Fractal dimension of green pepper was calculated, using the box-counting method (Sugihara and May 1990), from slides taken of well developed plants at the same distance from the side, focusing on the center of the plant.

To study the effect of stress on animals, we analyzed the fractal structure of the time distribution activity while feeding for female Spanish ibex under natural conditions, and under two stressful situations: advanced pregnancy and parasitic infection by Sarcoptes scabieis. We expect that behavioral feeding patterns vary in relation to energy available for maintenance. Feeding occurs in temporal bouts of different length, separated by gaps of different duration. When the animal interrupts its feeding to lift its head for just a moment, a head lift pattern is recorded. Number of head lifts per observation minute, on one hand, and feeding bout length and interfeeding time gap duration in seconds, on the other, were collected from focal females of Spanish ibex from the south of Spain during spring. A total of 22 female Spanish ibex were observed at Cazorla and Segura Mountains during May 1984. Each female was observed for at least $30 \mathrm{~min}$, and the number of head-lifts per min was noted. Twelve females showed advanced pregnancy and 10 manifested no sign of pregnancy.

During May 1994 a total of 32 females, 22 healthy and 10 sick, parasitized by Sarcoptes scabieis, were observed at Sierra Nevada. The infection started because of domestic goat transmission to the infected population, but no ecological differences exist between the healthy and sick females. This: allowed us to compare sick vs healthy females under identical ecological and physiological circumstances. Focal sampling for continuous periods of time during feeding activity was recorded by the researcher on a Psion Organizer computer with automatic time recording. Each time the animal activity changed was registered in the computer. Subsequently the data was converted into samples at one-second intervals.

The regression between cumulative frequency of headlifts per minute $(F(\Delta t))$ and time interval $(\Delta t)$ after log-log transformation, yields the dimension, $D$ (Hasting and Sugihara 1993) from the equation $F(\Delta t)=k \cdot(\Delta t)^{D}$.

The Mandelbrot-Weierstrass fractal exponent (Berry and Lewis 1980, Mandelbrot 1982) was calculated by applying the Fast Fourier Transform algorithm to the time series of the binary processes (feed $=1$, lag $=0$ ) over discrete intervals of one-second length. Time distribution activity was recorded for at least $1024 \mathrm{~s}$, and no longer than $4096 \mathrm{~s}$. The power spectrum of the FFT function is the square of the amplitude and is inversely related with the frequency $E(f)=k \cdot f^{-3}$, where $E(f)=$ power 
Table 2. One way analysis of covariance with the fractal dimension $D$ from the head lift frequency equation $F(\Delta t)=k \cdot(\Delta t)^{D}$, as dependent variable and phase of the reproductive cycle as fixed factor. Observation time is included as a covariant. Means, standard error and number are also included.

\begin{tabular}{lrccc}
\hline $\begin{array}{l}\text { Source of } \\
\text { variation }\end{array}$ & df & SS & F & P \\
\hline $\begin{array}{l}\text { Repr. cycle } \\
\text { minutes }\end{array}$ & 1 & 0.415 & 8.231 & 0.01 \\
Error & 1 & 0.253 & 5.007 & 0.04 \\
\hline
\end{tabular}

Means

Pregnant

Not pregnant

$0.898(12) \pm 0.07$

$1.184(10) \pm 0.07$

spectrum at frequency $f, k$ is a constant and $\beta$ is the Mandelbrot-Weierstrass exponent.

\section{Results and discussion}

We analyzed the effect of viral infection on the scale invariance of the leaf arrangement equation in green pepper, by comparing an infected and an uninfected population in plastic protected facilities. The results indicate that the infected population had higher developmental instability than the non-infected population. That is, the standard error of the regression $S_{y x}$ and the standard error of the parameter $\mathrm{a}, \mathrm{Sa}$, are significantly higher in the infected population, while the regression coefficient $R^{2}$ declines (Table 1).

So, in plants, because of their iterate modular nature, stress can be measured by the inconsistency of the geometrical relations between the plant's parts (Alados et al. 1994). Moreover, since stresses cause the plant to mobilize its resources and to reduce the amount of energy available for growth, we expect a reduction in the internode length with order. In consequence, the slope a from the equation $\mathrm{L}=\mathrm{k} \cdot \mathrm{N}^{\mathrm{a}} \cdot \mathrm{e}^{-\mathrm{bN}}$ significantly decreased in the diseased plants.

Plants develop fractal structures. The self-similar nature of branches provides a useful way to measure complexity by its fractal dimension. Branch structure of plants allows sufficient contact between the atmosphere and the chlorophyll to perform photosynthesis efficiently. We observed that healthy plants have larger fractal dimensions ( $\mathrm{D}=1.65$, se $=0.01, \mathrm{n}=20$ ) than infected plants $(\mathrm{D}=1.59$, se $=0.01, \mathrm{n}=19)$. The difference was significant when tested by one-way analyses of variance $\left(\mathrm{F}_{1,38}=8.42, \mathrm{P}<0.01\right)$.

To detect stress in wild animals, we analyzed the fractal structure of the time distribution activity, while feeding, for female Spanish ibex. Animals need to compromise in their use of time (or energy), between vigilance and feeding activities. If we consider the amount of energy intake of an organism to be fixed, the allocation of energy consumption into one component is necessarily at the expense of others.

We computed the fractal dimension, D, of the cumulative frequency of head lift over time intervals of duration $\Delta t$. The head-lift frequency $F(\Delta t)$ scales as: $F(\Delta t)=$ $\mathrm{k} \cdot(\Delta \mathrm{t})^{\mathrm{D}}$, where the scaling exponent measures the rate of head-lift frequency with the time interval. Comparisons between females with advanced pregnancy against nonpregnant females show a significant reduction in the fractal dimension (Table 2). When we compare females parasitized by Sarcoptes scabieis with apparently healthy females, we also observed a significant reduction in the fractal dimension with illness $\left(F_{1,30}=5.468, P=0.026\right)$, mean value is $1.146 \pm 0.05, \mathrm{n}=22$ for healthy females, $0.936 \pm 0.074, \mathrm{n}=10$ for sick females).

Food is consumed over the course of walking, alternating searching time with feeding bouts. The distribution of time between feeding bouts and the time gap represents the searching efficiency, especially during feeding hours in spring, when animals are mostly feeding in the same

\section{Healthy}

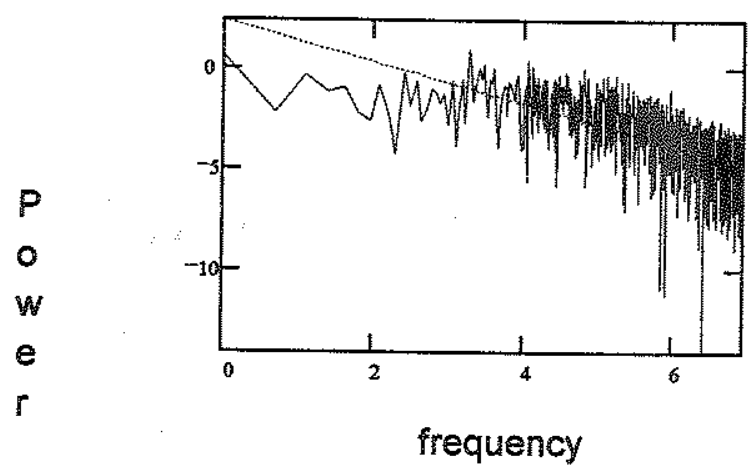

$S$

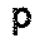

e

c

$\uparrow$

$r$

$u$

m

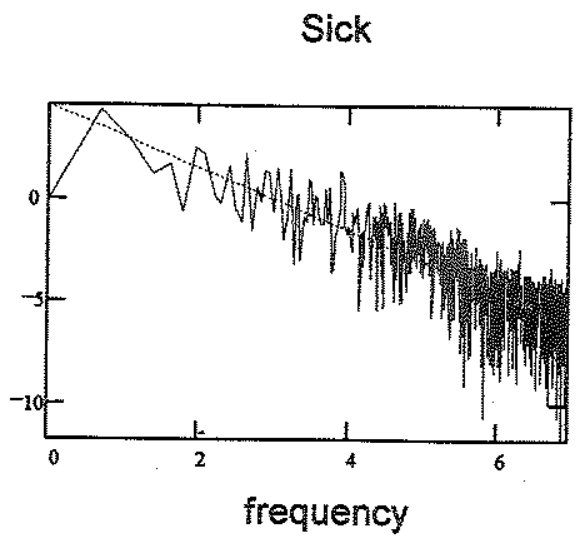

Fig. 1. Natural logarithm of the power spectrum against the natural logarithm of the frequency of time distribution feeding activity in healthy and unhealthy female Spanish ibex. 
ch or looking for adequate patches. In consequence we ect the complexity in the time distribution of feeding vity to be higher when animals are in better condition, wing them higher success in searching for food. ig. 1 shows the log-log relation between the power trum of the time distribution of feeding activity and frequency for healthy and unhealthy females. Our ts show a highly significant effect of poor health on 3 exponent, $\left(E_{1,2 s}=15.544, P<0.0001\right)$, with $\beta$ lower althy females (mean $=1.357 \pm 0.024, n=20)$ than in les with scabiosis (mean $=1.523 \pm 0.034, \mathrm{n}=10$ ). rences in the $\beta$ exponent in relation to the observaime were not significant (Wilcoxon test $z=0.169, P$ 366). Approximately the same mean values were ved when only sequences of $2048 \mathrm{~s}$ were included

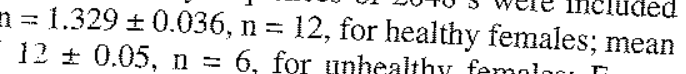
$12 \pm 0.05, n=6$, for inhealthy females; $F_{i, 16}=$
$P=0.01)$. relation between $\beta$ and the fractal dimension $D$ is discussion (Anguiano et al. 1994), but in all cases it ersely related, that is, the fractal dimension de-
$s$ under stress.

vious authors have used fractal dimension of walkths to measure searching efficiency in terms of utilization rather than in terms of encounter rate et al. 1992, Bundy et al. 1993). The fact that the dimension of particular structures is intrinsically ined ( $\mathrm{Ng}$ and Iannaccone 1992 in liver tissue,
et al. 1993 in neurons), is on in the renal arterial tree (Cross et al. 1994) and t vary between taxonomic groups (Smith et al. r cerebellar Purkinje cells, Garcia-Ruiz et al. 1990 honite sutures) makes fractal dimension a relevant idicator. Crist et al. (1992) observed that fractal on of pathway structure in different beetle species change over a broad range of microlandscape
eneity. tly, literature is giving enough evidence of a $\mathrm{n}$ in the fractal dimension of structures. For exhe fractal dimension of the pulmonary arteries $s$ from 1.62 to $1.5 \mathrm{in}$ hypoxic lungs and to $1.44 \mathrm{in}$ c lungs (Boxt et al. 1994). Renal arterial trees educed fractal dimension in congenitally abnoreys (Cross et al. 1993). Fractal dimension of tic bones declines in comparison with normal einstein et al. 1992). In horned ungulates, where has evolved structures to absorb the shock of counters, the complexity of the sagittal suture bone separation. The greater the fractal dimen(Long 1985). Under stress pronounced is its , fractal dimension of the skull sations due to Dama gazelle (Gazella dama) declines (Alados .). In plants, fractal dimension of branes (Alados lines with grazing stress (Alados et al. 1994) usion, we observe, on one hand, an increase in $c$ error resulting from stress where homeostaed because consistent relations between orga- nism parts are adaptive. This was observed in the case of plant leaf arrangement. On the other hand, where complexity is an advantage because it promotes increased efficiency (West and Goldberger 1987) in interchange with the environment, or because complexity buffers environmental variability (West 1990, Shinbrot et al. 1993), a reduction in complexity should accompany stress. That branch architecture out in the fractal dimension of distributions.

Acknowledgements - We thank Mojonera Experimental Station (INIA) for allowing us the use of its facilities to perform the providing access facilities to the expecially Laureano Cano for Vidal helped us with computer facilities population. Sebastian

\section{References} Alados, C. L., Escós, J. M. and Emlen, J. M. 1994. Scale
asymmetry: a tool to detect developmental instability under
the fractal geometry scope - In. tals in the natural and applied Novak, M. M. (ed.), FracNorth-Holland, pp. 25-36.

Anguiano, E., Pancorbo, fractal characterization and Aguilar M. 1994. Pitfalls in the quency analysis and proposal of a new mic surfaces by freM. M. (ed.), Fractals in the natural method. - In; Novak, (A-41). Elsevier, North-Holland, pp. $37-46$. Berry, M. V. and Lewis, Z Volland, pp. 37-46. delbrot fractal function. V. 1980. On the Weierstrass-Man484.

Boxt, L. M., Katz, J, Li.bovitch, L. S., Jones, R., Esser, and Reid, L. 1994. Fractal , L. S., Jones, R., Esser, P. D. the fractal dimension is lower in pulm of pulmonary arteries: J. Thorac. Imag. 9: 8-13.

Bundy, M. H, Gross, T. F, Coughlin, D. J. and Stricler, J. R. 1993. Quantifying copepod searching efficiency using 53: $15-28$.

Butler, G. C., Yamamoto, Y., Chen King, H., Northey, D. R. and Hughson, R. L. 1993. Heart rate variability and fractal di75: 2602-2612.

\section{Crist, T. O., Gert}

Animal movement . S., Wiens, J. A. and Milne, B. T. 1992. ment with Eleodes beetles in Ecol. 6: 536-544.

Cross, S. S., Start, R. D., Silcocks, P. B , Bull, A. D., Cotton, D. W. K. and Underwood, J C. P. B., Bull, A. D., Cotton, D.

renal arteri analysis. - J. Pathol. 170: $479-484$.
Freeman, D. C., Graham of the opmental stability in plants: symmetries, J. M. 1993. Develsis. - Genetica 89: 97-119.

Frontier, S. 1987. Applications

Legendre P. (ed.), Developments in NATO Series, Vol. G14. Springer, Berlin.
Garcia-Ruiz, J. M. Checal ecology. of ammonite sutures, - Paleobiol. 16:349-354 the origen Goldberger, A. L., Rigney, - Paleobiol. 16: 349-354. and fractals in human, D. R. and West, B. J. 1990. Chaos 35-41.

Graham, J. H., Freeman, D. C. and Emlen, J. M. 1993. Devel-
opmental stability: A sensitive indicator opmental stability: A sensitive indicator of population under
stress.- In: Landis, W. G. stress.- In: Landis, W. G., Hughes, J. S. and Lewis, M. A.
(eds), Environmental toxicology and ASTM STP 1179. American Society for Testing assessment. als, Philadelphia, pp. 136-158. 
Lasting, H. M. and Sugihara, G. 1993. Fractals: a user's guide for the natural sciences. - Oxford Univ. Press, Oxford.

ong, Ch. A. 1985. Intricate sutures as fractal curves. - J. Morphol. 185: 285-295.

fandelbrot, B. B. 1982. The fractal geometry of nature. Freeman, New York.

eale, E. A., Bowers, L. M. and Smith, T. G., Jr. 1993. Early dendrite development in spinal cord cell cultures: A quantitative study. - J. Neurosci. Res. 34: 54-66.

fg, Y. K. and Iannaccone, P. M. 1992. Fractal geometry of mosaic pattern demonstrates liver regeneration is a selfsimilar process. - Dev. Biol. 151: 419-430.

arsons, P. A. 1992. Fluctuating asymmetry: a biological monitor of envirommental and genomic stress. - Heredity 68 : $361-364$.

1993. The importance and consequences of stress in living and fossil populations: From life-history variation to evolutionary change. - Am. Nat. 142: S5-S20.

axman, G. J. 1956. Differentiation and stability in the development of Nicotiana rustica. - Ann. Bot. 20: 331-347.

hinbrot, T., Greobogi, C., Ot, E. and Yorke, J. A. 1993. Using small perturbations to control chaos. - Science 363: 411417.

Smith, T. G., Jr., Brauer, K. and Reichenbach, A. 1993. Quantitative phylogenetic constancy of cerebellar Puzkinje cell motphological complexity, - J. Comp. Neurol. 331: 402406.

Sugihara G. and May, R.M. 1990. Applications of fractals in ecology. - Trends Ecol. Evol. 5: 79- 86.

Waddington, C. H. 1957. The strategy of genes. ... Allen and Uniwin. London.

Waddington, J. L., MacCulloch, M. J. and Sambrooks, J. E. 1979. Resting heart rate variability in man declines with age. - Experientia 35: 1197-1198.

Weinstein, R. S. Majumdar, S. and Genat, H. K. 1992. Fractal geometry applied to the architecture of cancellous bone biopsy specimens. - Bone 13: A38.

West, B. J. 1990. Physiology in fractal dimension: error tolerance. - Ann. Biom. Engin. 18: 135-149.

- and Goldberger, A. L. 1987. Physiology in fractal dimensions. - Am. Sci. 75: 354-365.

Zakharov, V. 1987. Animal asymmetry: populations phenogenetic approach. - Nauka, Moscow. 